\title{
Questões LGBT em debate: sobre desafios e conquistas
}

\author{
Luiz Mello \\ Doutor em Sociologia (Universidade de Brasília) \\ Professor na Universidade Federal de Goiás \\ luizman@gmail.com \\ Camilo Braz \\ Doutor em Antropologia (Universidade de Campinas) \\ Professor na Universidade Federal de Goiás \\ camilobraz@gmail.com \\ Fátima Regina Almeida de Freitas \\ Mestranda na Universidade Federal de Goiás \\ fatimareginaalmeida@gmail.com \\ Rezende Bruno de Avelar \\ Doutorando na Universidade Federal de Goiás \\ revelas@gmail.com
}

Resumo Neste texto são apresentadas reflexões acerca da história recente do movimento LGBT no Brasil, com ênfase em seus principais desafios e conquistas. O que se destaca, neste contexto, é o caráter contraditório dos debates públicos acerca da cidadania de lésbicas, gays, bissexuais, travestis e transexuais, haja vista que sua humanidade não parece consensualmente reconhecida pelo conjunto da sociedade e que os discursos de grupos religiosos fundamentalistas tendem a questionar sua legitimidade como sujeitos de direitos a partir de um posicionamento político que coloca em xeque a laicidade do Estado. Também se reflete sobre o lugar dos poderes Executivo, Legislativo e Judiciário num cenário de incertezas jurídicas e morais, ressaltando-se a importância da construção de uma cultura política que reconheça a livre expressão da orientação sexual e das performances de gênero, para além dos parâmetros e valores da norma heterocêntrica.

Palavras-chave: movimentos sociais, ativismo LGBT, cidadania, direitos sexuais, Brasil.

\section{Movimento LGBT no Brasil: uma história de incertezas ${ }^{1}$}

$\mathrm{E}$ M SUA ReCente história de pouco mais de 30 anos, o atualmente chamado movimento LGBT (lésbicas, gays, bissexuais, travestis e transexuais) brasileiro já foi objeto de investigações acadêmicas im-

1. As reflexões apresentadas neste texto foram produzidas no contexto da pesquisa Movimentos sociais, direitos humanos e cidadania: um estudo sobre o movimento LGBT em Goiás, realizada pelo Ser-Tão, Núcleo de Estudos e Pesquisas em Gênero e Sexualidade, da Universidade Federal de Goiás, contando com apoio financeiro da Fundação de Amparo à Pesquisa do Estado de Goiás (Fapeg). Entre os integrantes da equipe de pesquisa, agradecemos especialmente a Fátima Regina Almeida de Freitas, Marcelo Perillo e Rezende Bruno Avelar pela interlocução e pela cumplicidade. 
portantes. ${ }^{2}$ A partir desse conjunto de trabalhos, é possível perceber que, entre o início dos anos 1980 e hoje, o movimento LGBT tornou-se um dos mais expressivos e visíveis do país, conseguindo pautar a questão dos direitos sexuais relativos ao que vem sendo chamado de orientação sexual e identidade de gênero em praticamente todas as instâncias da vida social: os poderes Executivo, Legislativo e Judiciário, os sistemas de educação, segurança e saúde, os meios de comunicação de massa, as universidades, outros movimentos sociais, sindicatos e associações profissionais, os partidos políticos, as igrejas, entre outros. Palavras e expressões como "homofobia", "homoafetividade", "homoparentalidade", "heteronormatividade", "sair do armário", "nome social", "lésbicas", "gays", "bissexuais", "travestis" e "transexuais", antes de uso restrito inclusive no universo da população LGBT, hoje são utilizadas ampla e crescentemente por vários setores da sociedade, especialmente pelos meios de comunicação de massa, o que contribui para a diminuição do estranhamento e do exotismo tradicionalmente associados a práticas sexuais não restritas ao universo da heterossexualidade.

Nesse cenário, a primeira conquista significativa e de alcance nacional do movimento LGBT brasileiro ocorreu em 1985 e decorre de decisão do Conselho Federal de Medicina (CFM), que deixou de definir a homossexualidade como patologia, como ocorria até então nos termos prevalecentes na Classificação Internacional de Doenças (CID), elaborada pela Organização Mundial de Saúde (OMS). A própria OMS passou a ter o mesmo entendimento a partir de $17 \mathrm{de}$ maio de 1990, data que se tornou marco histórico a ponto de este dia ser hoje internacionalmente reconhecido como Dia Mundial de Combate à Homofobia. Esse marco foi recentemente também referendado pelo governo federal, que, a partir de demanda do movimento LGBT, instituiu, por meio de Decreto Presidencial de 4 de junho de 2010, o dia 17 de maio como Dia Nacional de Combate à Homofobia.

Ainda em 1999, porém, o Conselho Federal de Psicologia (CFP) já estabelecera, por meio da Resolução $n^{\circ} 1$, o entendimento de que "os psicólogos não exercerão qualquer ação que favoreça a patologização de comportamentos ou práticas homoeróticas, nem adotarão ação coercitiva tendente a orientar homossexuais para tratamentos não solicitados" (art. $3^{\circ}$, caput).

Se a despeito das manifestações inequívocas do CFM, da OMS e do CFP em documentos públicos ainda existem disputas intensas em relação à (des)patologização da homossexualidade, os debates em torno da reivindicação de despatologização da transexualidade e da travestilidade são ainda incipientes e mais acirrados: tal desafio passou a ser enfrentado no Brasil e no mundo apenas muito recentemente.

Talvez a primeira tentativa mais sistemática de trazer para a arena política brasileira o debate sobre este tema seja a campanha internacional Stop Trans Pathologization - 2012, inicialmente proposta por grupos espanhóis, com o objetivo de excluir a transexualidade dos dois principais catálogos de doenças mentais vigentes: o DSM IV (Manual de Diagnóstico e Estatística das Perturbações Mentais), da American Psychiatric Association, cuja próxima versão revisada será divulgada em 2013, e a CID-10, da Organização Mundial de Saúde, que sairá em 2014. Esse relativo atraso na reivindicação política de despatologização

2. Cabe notar, nesse sentido, as pioneiras pesquisas de Edward MacRae (1990), sobre o Grupo Somos, de São Paulo, e de Cristina Câmara (2002), sobre o Grupo Triângulo Rosa, do Rio de Janeiro, apresentadas como tese de doutorado e dissertação de mestrado, respectivamente. Já nos anos 2000, destacam-se também os trabalhos de Augusto Andrade (2002), sobre o Grupo Arco-Íris, do Rio de Janeiro, de Regina Facchini (2005), sobre o Grupo Corsa, de São Paulo, e de Felipe Bruno Martins Fernandes (2007), sobre o Grupo Cellos, de Belo Horizonte, defendidas como dissertação de mestrado, além da tese de doutorado de Fernando Luiz Alves Barroso (2007), sobre o Grupo Nuances, de Porto Alegre. Por sua vez, outras pesquisas procuraram compreender a dinâmica de atuação do movimento LGBT em contextos locais específicos, como as investigações de Gabriele dos Anjos (1999), relativas a Porto Alegre; de Isadora Lins de França (2006) e Gustavo Gomes da Costa Santos (2006), referentes a São Paulo; de Fernando José Taques (2007), concernente a Santa Catarina; de Alírio Melo Urany (2008), com foco em Goiânia; e de Renata Lúcia Camarotti Câmara Escorel Riberio (2009), privilegiando os contextos baiano e nacional. Também devem ser destacados os trabalhos que têm como objeto de reflexão a atuação política de segmentos específicos do ativismo LGBT, como a tese de doutorado de Guilherme Almeida (2005) e as dissertações de mestrado de Maria Célia Orlato Selem (2007), de Regina Coeli Benedito dos Santos (2006) e de Patrícia Lessa dos Santos (2007), sobre o movimento lésbico, e a tese de doutorado de William Siqueira Peres (2005) sobre organização política de travestis. Há ainda trabalhos que visam a uma análise mais ampla do movimento LGBT no cenário nacional, sem se reportar a um contexto local/regional específico, como os de Michele Conde (2004), Vera Lúcia Marques da Silva (2008), Regina Facchini (2009) e, ainda, Júlio Simões e Regina Facchini (2009). Por fim, outras investigações buscam compreender a atuação política do movimento LGBT a partir de realidades nacionais diversas, a exemplo da tese de doutorado de Alessandro Soares da Silva (2006) e da dissertação de mestrado de Guilherme Rodrigues Passamani (2009). Cabe aqui destacar que há várias outras contribuições fundamentais para a compreensão das dinâmicas culturais, sociais e políticas relativas à homossexualidade no Brasil, privilegiando-se, de uma maneira geral, a homossexualidade masculina, embora seu foco principal não seja a caracterização do movimento homossexual brasileiro, como conhecido em suas origens, ou LGBT, em sua feição mais contemporânea, a exemplo dos trabalhos de Peter Fry (1982), Peter Fry e Edward MacRae (1983), Leila Míccolis e Herbert Daniel (1983), João Silvério Trevisan (1986), Luiz Mott (1987), James Green (2000), Carmen Dora Guimarães (2004), entre outros. São mais recentes, embora cada vez mais abundantes, os trabalhos acadêmicos sobre transexualidades e travestilidades, com destaque para as contribuições de Marcos Renato Benedetti (2005), Berenice Bento (2006), Don Kulick (2008), Larissa Pelúcio (2009) e Tiago Duque (2011). Deve-se ressaltar, porém, que ainda são raras as investigações que privilegiam a compreensão do movimento político organizado com foco em identidades de gênero dissidentes em relação à heteronormatividade. 
da transexualidade talvez decorra daquilo que Butler (2009) chamou de "paradoxo da autonomia": o acesso a mudanças corporais reivindicadas por transexuais só se tornou possível no Brasil - e na maior parte do mundo - por meio da explícita patologização da transexualidade, cujo "tratamento" consiste em um conjunto de procedimentos médicos e cirúrgicos da chamada readequação sexual. Ao se reivindicar a despatologização, corre-se o risco de perder-se, em contrapartida, o acesso aos procedimentos cirúrgicos, endocrinológicos e clínicos integrantes do processo transexualizador.

Cabe destacar que o Ministério da Saúde implantou o processo transexualizador no âmbito do Sistema Único de Saúde (SUS), por meio da Portaria $n^{\circ} 1.707$, de 18 de agosto de 2008, em serviços de referência devidamente habilitados, atualmente existentes em quatro capitais: Goiânia, Porto Alegre, Rio de Janeiro e São Paulo. Trata-se da regulamentação, em âmbito nacional, de uma política que engloba cirurgia, assistência e cuidados com os transexuais, mas que não assegura aos beneficiários o acesso aos procedimentos judiciais necessários à mudança de sexo e nome em seus documentos civis. Essa realidade revela-se um contrassenso, já que o serviço público de saúde custeia todo o processo de readequação sexual de transexuais, mas o Estado brasileiro não reconhece a tais sujeitos o direito de viver como cidadãos em suas novas identidades de gênero, já que não existe nenhuma lei que discipline a mudança de nome e sexo de transexuais e cada sujeito deve recorrer individualmente ao Poder Judiciário para assegurar tal direito, torcendo para que um juiz mais liberal autorize o reconhecimento legal de sua nova identidade civil. ${ }^{3}$

$\mathrm{Na}$ atualidade, o movimento LGBT brasileiro faz-se mais visível por meio da organização de manifestações de rua, conhecidas como "Paradas do Orgulho LGBT", que reúnem milhões de pessoas ao longo de todo ano, em centenas de eventos realizados em cidades de todo o país, inclusive onde os grupos têm níveis de institucionalização bastante frágeis. No Brasil, existe um forte debate, inclusive entre ativistas, acerca do caráter político versus caráter festivo dessas paradas. Por um lado, há críticas severas ao fato de talvez serem manifestações públicas excessivamente dionisíacas, que em muito se aproximam de "carna- vais fora de época", que não conseguem transformar a visibilidade pública em ações políticas concretas, como a aprovação de projetos de lei, a eleição de parlamentares comprometidos com questões LGBT ou a efetiva implementação de políticas públicas de combate à homofobia em áreas consideradas muitas vezes prioritárias, como educação, saúde e segurança. Por outro, há quem defenda que é inegável o efeito desestabilizador de determinadas convenções sociais heteronormativas que a saída às ruas, em plena luz do dia, de dezenas de milhares de lésbicas, gays, bissexuais, travestis e transexuais, e não apenas nas grandes metrópoles, pode vir a acarretar, ao positivar expressões sexuais e de gênero construídas historicamente como anormais e abjetas. $\mathrm{O}$ debate persiste, e depende em certa medida da maneira como se conceitua o que é ou não "política".

A fragmentação identitária também tem sido outra característica do movimento LGBT no Brasil. Essa pluralidade do movimento manifesta-se na constatação de que existem organizações mistas, como a pioneira Associação Brasileira de Lésbicas, Gays, Bissexuais, Travestis e Transexuais (ABGLT), fundada em 1995, mas também um número crescente de outras que representam segmentos específicos, como a Associação Brasileira de Lésbicas (ABL), a Liga Brasileira de Lésbicas (LBL), a Associação Nacional de Travestis e Transexuais (Antra), o Coletivo Nacional de Transexuais (CNT), a Associação Brasileira de Gays (Abragay) e a Articulação Brasileira de Gays (ArtGay). Outras organizações representam segmentos ainda mais específicos, a partir de atributos identitários como raça/cor e idade, a exemplo da Rede Afro GLBT, o Coletivo Nacional de Lésbicas Negras Feministas Autônomas (Candaces - BR) e a Rede E-Jovem. A demonstrar o crescimento de uma visibilidade identitária no interior da própria ABGLT, a Carta de Belém aprovada no III Congresso da Associação, realizado em 2009, além de trazer uma análise da conjuntura e as principais ações propostas para o biênio 2009/2010, faz referência específica a reivindicações políticas relativas a travestis e transexuais, mulheres lésbicas e bissexuais, juventude LGBT, pessoas LGBT idosas, LGBT negros e indígenas, pessoas com deficiência e gays, bissexuais e travestis vivendo com HIV/Aids.

A atuação política de representantes deste multifacetado movimento LGBT brasileiro também

3. Por outro lado, a partir de pressão de grupos organizados, redes e associações de atuação nacional, como a Articulação Nacional de Travestis, Transexuais e Transgêneros (Antra) e a Associação Brasileira de Lésbicas, Gays, Bissexuais, Travestis e Transexuais (ABGLT), desde 2009 tem-se observado um movimento crescente de aprovação de atos normativos relativos ao uso de nome social por pessoas travestis e transexuais, com destaque para a Portaria n 233, de 18 de maio de 2010, que assegura direito a uso de nome social a servidores da administração pública federal, bem como da Portaria n 675, de 30 de março de 2006, que aprova a Carta dos Direitos dos Usuários da Saúde, que prevê o direito de o paciente ser tratado pelo nome de sua preferência, ainda que não se faça no documento referência expressa a pessoas travestis e transexuais. A despeito da importância destas iniciativas, deve ser registrado seu alcance limitado, já que não assegura a pessoas travestis e transexuais a efetiva garantia de escolha de seus nomes e sexos, que deveriam passar a constar em todos os seus documentos de identificação civil, e não apenas em registros específicos, o que só reforça as situações potenciais de discriminação decorrentes da não inserção social incondicional e plena. 
tem se dado por meio da participação em grupos de trabalho, fóruns e conselhos municipais, estaduais e nacional de diversidade sexual ou de direitos da população LGBT, bem como em outros, como de saúde, direitos humanos, segurança e da mulher. Além disso, em 2008 ocorreu grande mobilização de militantes com vistas à participação em conferências municipais, estaduais e nacional LGBT, ocasião em que foram formalmente apresentadas demandas prioritárias aos governos, em seus diferentes níveis. Concomitantemente, também foi recorrente a participação de um grupo pequeno, mas atuante, de ativistas em outras conferências temáticas, como de educação, saúde, segurança e direitos humanos, com o objetivo de inserir na pauta destas áreas de atuação governamental as demandas do movimento LGBT, que incluem o combate à discriminação contra lébicas, gays, bissexuais, travestis ou à homofobia, em todas as suas manifestações.

Muito embora sinalize para um contexto em que o Estado figura como potencialmente aberto ao diálogo em relação às demandas dos movimentos sociais, um dos riscos desta relação entre Estado e sociedade civil é exatamente o clientelismo (Carrara, 2005), já que muitas vezes o governo passa a ser o principal financiador dos grupos que integram tais movimentos, esperando, como contrapartida, que estes realizem ações e projetos que deveriam ser executados por órgãos governamentais específicos de áreas diversas, como saúde, educação e segurança. Ao ocupar o lugar do Estado na gestão da coisa pública, tais grupos podem perder sua autonomia para realizar o controle social e o monitoramento das ações governamentais, atribuição central no processo de construção de políticas públicas democráticas. Como destacam Regina Facchini e Isadora França:

Atualmente, o envolvimento da sociedade civil na elaboração e na implementação de políticas públicas coloca em xeque o próprio lugar de "outro do Estado". Com a "resposta coletiva" à epidemia do HIV/ aids e outras experiências de "parceria" entre Estado e sociedade civil, vários sujeitos políticos têm encontrado saídas para a visibilização e o encaminhamento de suas demandas, e até mesmo para a manutenção da estrutura necessária à atuação de suas organizações. No entanto, os efeitos do envolvimento da sociedade civil nas atribuições tradicionalmente tidas como de responsabilidade do Estado não são ainda muito claros ou previsíveis, embora certamente se estendam para além do impacto já citado sobre o formato das organizações, os modos de atuação e a dinâmica das relações internas ao movimento. (2009, p. 71)
A esse respeito, em uma pesquisa realizada acerca da trajetória do movimento LGBT no estado de Goiás, ${ }^{4}$ foi possível verificar, a partir dos relatos de militantes, algumas situações exemplares. Ao menos em duas cidades do interior, enquanto as organizações do movimento necessitavam de uma sede para funcionar e não possuíam recursos para pagamento de aluguel, a prefeitura oferecia-lhes uma sala para o desenvolvimento de atividades que, a rigor, seriam de responsabilidade do Estado - como, por exemplo, ações de prevenção e combate às DST-Aids (Braz, Mello et al., 2011).

A partir da ampliação das ações governamentais voltadas à promoção da cidadania e dos direitos humanos de tais grupos e/ou em áreas prioritárias da agenda social e política, outro fenômeno observado tem sido a crescente contratação de ativistas de movimentos sociais diversos para atuar como técnicos e gestores governamentais, geralmente por meio da nomeação em cargos de confiança. Se os riscos de cooptação e perda da autonomia crítica das lideranças já eram grandes, considerando a profissionalização do ativismo e o fato de que os governos têm sido parceiros e/ou financiadores das ações dos grupos da sociedade civil, quando o ativista se torna gestor tem-se maior possibilidade de confusão de lugares e atribuições. Ou seja, quando o ativista de ontem é o gestor de hoje, muitas vezes continua a pensar e a agir como ativista e/ou entra em conflito com seus antigos aliados de lutas cotidianas e de projetos utópicos. Isso para não falar nos casos em que ativistas, além de gestores, são também filiados a partidos políticos e estão às voltas com as dificuldades de compatibilização entre diferentes níveis de alianças, lealdades e compromissos ideológicos. No sentido proposto por Pierre Bourdieu (1983), então, se no campo interno ao movimento LGBT as disputas já são grandes, quando um mesmo grupo de sujeitos passa a atuar em diversos campos, a possibilidade de conflitos e de disputas de poder e prestígio tende a aumentar.

A despeito do esforço de organização do movimento e de participação de ativistas em várias frentes de luta, uma crítica sistemática que tem sido feita, desde o interior das próprias organizações militantes, diz respeito ao distanciamento dos grupos em relação aos indivíduos concretos que pretenderiam representar. Nas falas de muitos ativistas, tal processo é geralmente definido como a distância existente entre a militância e a chamada "comunidade" LGBT. Muitas vezes, reclama-se que tais indivíduos parecem não reconhecer - ou sequer conhecer - as lideranças que pretendem representá-los e não estão sensibilizados para a importância da atuação política com vistas à garantia de direitos que impactaria positivamente suas condi- 
ções imediatas de vida. O que se observa em decorrência disso é a dificuldade de mobilização massiva para ações coletivas que visam à aprovação de projetos de lei ou à pressão sobre o Poder Executivo para a efetiva implantação de ações de combate à homofobia. Outra característica desse distanciamento parece ser o número reduzido de grupos existentes no país, já que um número aproximado de 200 organizações LGBT no Brasil parece pouco significativo quando se considera as dimensões geográficas e populacionais do país. Além disso, cada grupo geralmente é constituído por um número reduzido de ativistas, especialmente quando se pensa nas pessoas que atuam cotidianamente nas organizações, muitas vezes pouco escolarizados e qualificados para a execução de atividades de advocacy mais sistemáticas. Tal escassez de lideranças se mostra ainda mais preocupante ao se constatar a diminuição das possibilidades de profissionalização do ativismo, dada a redução de recursos governamentais para o financiamento de atividades dos grupos. Não é à toa que o trabalho de advocacy junto aos poderes legislativos federal, estadual e municipal tem-se mostrado tão difícil, especialmente diante do fortalecimento de grupos religiosos que transformaram o combate a direitos sexuais e reprodutivos em sua principal bandeira de luta na esfera pública.

\section{Políticas públicas para a população LGBT: o que há é quase nada}

É muito recente, deve-se outra vez registrar, o processo de institucionalização de políticas públicas para a população LGBT no Brasil, ${ }^{5}$ iniciado apenas em 2004, com a publicação do Programa Brasil sem Homofobia, que em sua elaboração contou com a participação de ativistas ligados a grupos LGBT de distintas partes do país. Neste contexto, podem ser destacados pelo menos seis marcos importantes relativos à promoção de políticas públicas voltadas à população LGBT, em nível federal, e que são resultado do trabalho de advocacy dos grupos organizados junto ao Poder Executivo:

- realização, em 2008, da I Conferência Nacional de Gays, Lésbicas, Bissexuais, Travestis e Transexuais, com o tema Direitos Humanos e Políticas Públicas: o Caminho para Garantir a Cidadania de Gays, Lésbicas, Bissexuais, Travestis e Transexuais (GLBT);
- divulgação do Plano Nacional de Promoção da Cidadania e Direitos Humanos de Lésbicas, Gays, Bissexuais, Travestis e Transexuais PNDCDH-LGBT (2009);

- lançamento do Programa Nacional de Direitos Humanos (PNDH 3), em 2009; ${ }^{6}$

- criação da Coordenação Geral de Promoção dos Direitos de LGBT, vinculada ao Departamento de Promoção dos Direitos Humanos, da Subsecretaria Nacional de Promoção e Defesa dos Direitos Humanos, da Secretaria de Direitos Humanos (2009);

- criação do Conselho Nacional de Combate à Discriminação - LGBT, vinculado à Secretaria de Direitos Humanos (2010);

- realização, em 2011, da II Conferência Nacional de Políticas Públicas e Direitos Humanos de LGBT, com o tema Por um País Livre da Pobreza e da Discriminação - Promovendo a Cidadania de Lésbicas, Gays, Bissexuais, Travestis e Transexuais.

Todavia, as ações e programas formulados pelo governo federal - e também pelos governos estaduais e municipais - com vistas ao combate à homofobia e à promoção da cidadania da população LGBT são marcados pela fragilidade institucional e por deficiências estruturais, tendo em vista: a) a ausência de respaldo jurídico que assegure sua existência como políticas de Estado, livres das incertezas decorrentes das mudanças na conjuntura política, da homofobia institucional e das pressões homofóbicas de grupos religiosos fundamentalistas; b) as dificuldades de implantação de modelo de gestão que viabilize a atuação conjunta, transversal e intersetorial, de órgãos dos governos federal, estaduais e municipais, contando com a parceria de grupos organizados da sociedade civil; c) a carência de previsão orçamentária específica, materializada no Plano Plurianual (PPA), na Lei de Diretrizes Orçamentárias (LDO) e na Lei Orçamentária Anual (LOA); e d) o reduzido número de servidores públicos especializados, integrantes do quadro permanente de técnicos dos governos, responsáveis por sua formulação, implementação, monitoramento e avaliação (Mello, 2010).

A segunda Conferência Nacional LGBT, realizada em dezembro de 2011, foi um bom termômetro para constatar mudanças no cenário da luta por direitos para a população LGBT no Brasil, particularmente em face da forte pressão de grupos religiosos sobre

5. Para uma análise detalhada, ver o relatório Políticas públicas para a população LGBT no Brasil: um mapeamento crítico preliminar, produzido pela equipe do Ser-Tão, com apoio financeiro da Secretaria de Direitos Humanos, da Presidência da República, e da Fundação de Amparo à Pesquisa do Estado de Goiás (Fapeg). Disponível em: <www.sertao.ufg.br/politicaslgbt>.

6. Cabe sinalizar que o PNDH 3 não se restringe à problemática LGBT, muito embora traga em seu interior proposições voltadas para tal segmento populacional. Nesse sentido, sua formulação é fruto das reivindicações de um conjunto mais amplo de sujeitos políticos envolvidos na busca por cidadania e na luta em defesa dos direitos humanos. 
o governo federal. Enquanto o então presidente Lula foi ovacionado pelos delegados na abertura da I Conferência em 2008, nessa segunda, a presidenta Dilma Rousseff não esteve presente, nem enviou qualquer saudação aos participantes do evento. O clima entre os delegados representantes da sociedade civil era de clara reação à falta de medidas mais objetivas do Poder Executivo com vistas a implementar de maneira consistente e continuada as propostas integrantes do Plano Nacional LGBT e do PNDH 3. Em contrapartida, os representantes ministeriais que participaram do Painel Políticas Públicas e Direitos da População LGBT $^{7}$ e do Painel Políticas de Inclusão Social e Cidadania da população $\mathrm{LGBT}^{8}$ apresentaram relatos de iniciativas do governo federal, procurando incensar um conjunto de medidas que os referidos delegados não reconheciam como minimamente suficientes para combater o crescimento do discurso de ódio e da violência contra pessoas LGBT no Brasil. Especialmente desde o reconhecimento, em maio de 2011, pelo Supremo Tribunal Federal, das uniões entre pessoas do mesmo sexo como uniões estáveis, iguais em direitos aos núcleos familiares constituídos por casais de pessoas de sexos diferentes, com ou sem filhos. Diante do cenário de recrudescimento da homofobia no Brasil e da relativa paralisia das ações governamentais no âmbito dos direitos sexuais, em todos os níveis de governo, palavras de ordem prevalecentes na II ${ }^{a}$ Conferência Nacional LGBT foram pela efetiva garantia da laicidade do Estado, da integridade física e dos direitos civis da população LGBT.

\section{Demandas legislativas, conquistas judiciais}

Embora no Brasil não haja uma lei federal que reconheça a igualdade jurídica entre todos os casais, independentemente dos sexos de seus integrantes, os direitos conjugais começaram a deixar de ser um monopólio do par heterossexual a partir de um conjunto pontual e recente de iniciativas do Poder Executivo federal, a exemplo da Súmula Normativa $\mathrm{n}^{\circ} 12$, de 4 de maio de 2010, da Agência Nacional de Saúde Suplementar (ANS), que assegura o direito de inclusão de companheiro do mesmo sexo como beneficiário titular de plano privado de assistência à saúde, e do Parecer $n^{\circ}$ 1503, de 19 de julho de 2010, da Procuradoria-Geral da Fazenda Nacional (PGFN), que permitiu a inclusão cadastral de "companheiro/a homoafetivo/a" como dependente para fins do Im- posto sobre a Renda da Pessoa Física. Essa situação tornou-se ainda mais inconteste quando, em 5 de maio de 2011, o Supremo Tribunal Federal (STF), por unanimidade, reconheceu as relações afetivo-sexuais entre pessoas do mesmo sexo como entidades familiares. No contexto desta votação, ficou evidenciado o entendimento do STF de que não existe qualquer amparo legal/constitucional para a discriminação de pessoas em função de orientação sexual, inclusive no âmbito dos direitos relativos à família.

Quando se poderia imaginar que essa decisão estabeleceria o entendimento pacificado de que não existe qualquer amparo legal/constitucional para a discriminação por orientação sexual ou identidade de gênero no Brasil e que é impossível, portanto, tentar apoiar com argumentos jurídicos o preconceito e a intolerância contra sujeitos que não vivem em conformidade à heterossexualidade compulsória, o que se observou foi uma onda de forte reação homofóbica, liderada por um grupo reduzido mas ruidoso de parlamentares vinculados a grupos religiosos fundamentalistas, que questionaram a legitimidade da atuação do STF e insistiram na tese de que seria prerrogativa exclusiva do Congresso Nacional definir o entendimento jurídico relativo ao estatuto das uniões homossexuais. Como sinalização do extremismo e da recusa deste grupo à decisão do STF, o deputado federal João Campos, do PSDB de Goiás, presidente da Frente Parlamentar Evangélica, apresentou o Projeto de Decreto Legislativo (PDC) no 224/11 visando suspender os efeitos da decisão do STF. Contrariando a intenção do autor, no entanto, a presidência da Câmara dos Deputados não acatou a apresentação do projeto, por sua flagrante ilegalidade.

Outras reações imediatas à decisão do STF também se materializaram por meio de articulações promovidas pela Frente Parlamentar Evangélica, cujos integrantes passaram a atacar de maneira sistemática a iniciativa do Ministério da Educação de apoiar o Projeto Escola sem Homofobia, que previa a distribuição de 6 mil "kits anti-homofobia" para escolas públicas de ensino médio de diferentes partes do Brasil. O que se viu a partir daí foi uma massiva campanha produzida especialmente por parlamentares religiosos e pastores evangélicos que passaram a nomear o material educativo produzido com apoio do MEC de "kit gay", em meio a um clima de pânico moral que o apresentava como um inaceitável estímulo a práticas homossexuais entre crianças e adolescentes. A reação da presidenta Dilma Rousseff à pressão dos parlamentares foi suspender a distribuição do material, mesmo antes de consultar

7. Participaram deste painel representantes dos ministérios da Saúde e da Educação e da Secretaria Geral da Presidência da República. O representante do Ministério do Trabalho e Emprego, apesar de previsto na programação, não compareceu ao evento.

8. Participaram deste painel representantes dos ministérios da Cultura, da Justiça e do Desenvolvimento Social e da Secretaria de Direitos Humanos. 
Fernando Haddad, então ministro da Educação, quanto à sua pertinência. No entendimento da presidenta, não se deveria fazer "propaganda de opções sexuais" e todo material que tratasse de temas relativos a "costumes", em qualquer área de atuação do governo federal, e não apenas na de Educação, teria que passar pelo crivo da Coordenação-Geral da Presidência e por um amplo debate com a sociedade civil. ${ }^{9}$

Ao não garantir a laicidade do Estado brasileiro e apoiar o discurso religioso homofóbico em ascensão no país, a presidenta deslegitimou todo o trabalho de advocacy realizado pelo movimento LGBT junto ao governo federal em três décadas de construção de um ideário de combate à homofobia no País. Nada disso é surpreendente, se recordarmos a campanha eleitoral da presidenta Dilma Rousseff em fins de 2010, quando se observou uma forte reação de setores religiosos fundamentalistas a seu eventual apoio a demandas da população LGBT e ao aborto, ainda que seu programa de governo não fizesse qualquer alusão a tais temas. Diante da radicalização da intolerância e das pressões religiosas, a então candidata chegou a divulgar uma carta pública dirigida a eleitores cristãos, na qual expressa seu compromisso de não apoiar propostas legislativas relativas à cidadania de pessoas LGBT e ao aborto. A consequência primeira deste tipo de compromisso, materializada no veto à distribuição do kit anti-homofobia, é que a defesa pública da homofobia encontrou explícito respaldo institucional e governamental, já que a fala da presidenta passou a ser utilizada para justificar a homofobia prevalecente e cada vez mais ostensiva, particularmente desde a decisão do STF. ${ }^{10}$

Neste mesmo ritmo de resistência religiosa, em 17 de junho de 2011, um juiz da $1^{\text {a }}$ Vara da Fazenda Pública de Goiânia, que também é pastor da Igreja Assembleia de Deus, anulou o primeiro registro de união estável realizado no Brasil pós-decisão do STF, em 9 de maio do mesmo ano, entre Liorcino Mendes, presidente da Articulação Brasileira de Gays (ArtGay) e diretor executivo da ABGLT, e Odílio Torres. Imediatamente após a divulgação da sentença, a Ordem dos Advogados do Brasil (OAB) divulgou nota, considerando a iniciativa do juiz um "retrocesso moralista". Esta decisão judicial foi anulada em 21 de junho, restabelecendo-se a validade do registro realizado. Mesmo assim, no dia seguinte, o juiz-pastor foi recebido no Congresso Nacional como herói por integrantes da Frente Parlamentar Evangélica, manifestando-se sobre sua sentença nos seguintes termos: "Deus me incomodou, Deus como que me impingiu a decidir".

Em contrapartida, em 28 de junho de 2011, coincidentemente Dia Internacional do Orgulho LGBT, pela primeira vez um casal de homens, da cidade de Jacareí, em São Paulo, juntos há oito anos, e outro de mulheres, moradoras de Brasília, juntas há 11 anos, puderam converter seus registros de união estável em casamento civil, a partir de sentenças judiciais fundadas na decisão do STF de 5 de maio. Considerando que essas duas sentenças não poderão ser revogadas em nenhuma instância do Poder Judiciário, já que contaram com a anuência do Ministério Público, passou-se a ter uma situação jurídica em que o casamento entre pessoas do mesmo sexo já é uma realidade no país, embora o Congresso Nacional ainda se recuse a aprovar qualquer projeto de lei que normatize vínculos conjugais entre pessoas do mesmo sexo. ${ }^{11}$

Este parece ser o destino que aguarda o Projeto de Lei da Câmara (PLC) no 122, de autoria da então deputada Iara Bernardes, apresentado em 2001, que propõe a criminalização da discriminação por orientação sexual nos moldes da lei que criminaliza o racismo, e também passou a ser objeto de oposição extremada de parlamentares e grupos religiosos desde sua aprovação na Câmara dos Deputados, em 2006, quando iniciou sua tramitação no Senado Federal, e especialmente desde a decisão do STF. O principal argumento utilizado pelos opositores à aprovação do PLC n 122 é que seria direito de expressão, assegurado na Constituição Federal, promover a condenação da homossexualidade a partir de quaisquer argumentos, inclusive bíblicos, sem que isso implique homofobia passível de punição nos termos previstos no projeto em debate. A partir deste argumento, toda e qualquer possibilidade de negociação com vistas à aprovação do PLC mostrou-se inviável, mesmo quando a senadora Marta Suplicy, relatora da proposição, já havia anunciado publicamente que acrescentaria uma emenda ao texto, de forma a garantir o direito de religiosos condenarem a homossexualidade no âmbito dos cultos. Diga-se de passagem que essa tentativa extremada de encontrar um caminho

9. Como divulgado amplamente nos meios de comunicação de massa, a decisão da presidenta teria sido motivada pela ameaça de parlamentares da bancada evangélica de apoiar a convocação do então ministro da Casa Civil, Antonio Palocci, braço forte do governo Dilma, para explicar sua "evolução patrimonial" suspeita, caso não fosse tomada uma medida efetiva e decisiva contra a divulgação do kit.

10. Em fevereiro de 2012, o Ministério da Saúde determinou a retirada da internet de vídeo dirigido a jovens gays de 18 a 24 anos, produzido pelo Departamento de DST, Aids e Hepatites Virais, no contexto das campanhas de prevenção ao HIV/Aids do carnaval. Tudo leva a crer que a decisão foi motivada por pressões de grupos religiosos, embora representantes do Ministério da Saúde afirmem que o material tenha sido produzido apenas para veiculação em ambientes fechados.

11. Em 25 de outubro de 2011, o Superior Tribunal de Justiça (STJ) assegurou a um casal de mulheres do Rio Grande do Sul o direito de serem legalmente reconhecidas como civilmente casadas. A decisão não cria um efeito vinculante (como no caso da do STF), mas estabelece jurisprudência pioneira, sinalizando claramente o entendimento dos tribunais superiores brasileiros de que o casamento não é mais uma instituição restrita ao casal homem-mulher. 
que viabilizasse a aprovação do projeto explicita os impasses que caracterizaram as negociações, já que o alcance da lei que fizesse esse tipo de concessão estaria completamente limitado - basta imaginar uma lei de combate ao racismo e ao machismo que assegurasse o direito de se condenar negros, judeus e mulheres a partir de argumentos religiosos. $\mathrm{O}$ que estes embates têm mostrado é que contra a homofobia radical não há diálogo possível: os insultos, como destaca Didier Eribon (2008), são, também nesses casos, vereditos. O que nos mostra, uma vez mais, que os discursos, ou a "cultura", produzem efeitos materiais e práticos bastante significativos - e muitas vezes nefastos - em nossas vidas.

Além do PLC n ${ }^{\circ}$ 122/06, tramitam no Congresso Nacional dezenas de proposições legislativas dispondo sobre combate à homofobia e/ou garantia de direitos à população LGBT, bem como um número crescente que pretende vedar direitos conjugais e parentais a casais de pessoas do mesmo sexo ou relativos ao processo transexualizador. No cenário atual, projetos "pró-LGBT" parecem não ter a menor perspectiva de serem apreciados pelo Poder Legislativo, considerando-se a pressão de parlamentares vinculados a grupos religiosos fundamentalistas e à atual radicalização do discurso homofóbico no Congresso Nacional e na sociedade brasileira em geral. Aqui vale destacar que é notória a ausência de parlamentares lésbicas, gays, bissexuais, travestis e transexuais, nos três âmbitos de atuação do Poder Legislativo: as câmaras municipais, as assembleias estaduais e o Congresso Nacional (Câmara dos Deputados e Senado Federal). Se o número de candidatos pertencentes ao universo LGBT é baixo, os que quando eleitos se comprometem com as bandeiras do movimento LGBT são ainda mais minoritários. Basta lembrar que, em mais de 100 anos de vida republicana, o primeiro homem gay e abertamente comprometido com a questão LGBT foi eleito para a Câmara dos Deputados apenas em 2010, o deputado Jean Willys, do PSOL.

\section{Ainda muito longe do fim}

No Brasil e no mundo, as lutas políticas em torno da garantia de direitos civis para lésbicas, gays, bissexuais, travestis e transexuais ainda está muito longe do fim. Não há aqui, nos EUA, na França, em Uganda ou no Japão, para ficarmos com alguns exemplos aleatórios, um acordo social minimamente pactuado que assegure os direitos civis de integrantes destes segmentos sociais. A homofobia de Estado institucionalizada legalmente na forma de desproteção jurídica para pessoas LGBT em várias esferas da vida social não encontra nenhum paralelo quando compa- rada a outras fontes de opressão, como o machismo e o racismo, mesmo nos ditos países democráticos na contemporaneidade.

Quando se pensa em uma perspectiva comparada, porém, não há dúvidas de que o movimento LGBT já materializou muitas conquistas para pessoas que até poucos anos eram percebidas como inexistentes, moralmente poluídas ou sem valor social, invisibilizadas que estavam na arena política e sem representantes concretos dispostos a assumir os riscos de afirmar a legitimidade do desejo sexual entre pessoas do mesmo sexo, dos projetos de vida conjugal que não se conformam aos parâmetros do casal homem-mulher aberto à reprodução e das performances de gênero que questionam a naturalidade e a univocidade das possibilidades de existência humana. Hoje, como nunca, o debate sobre direitos civis de pessoas LGBT está na ordem do dia. Mas também hoje, como jamais se viu, a homofobia fundada em argumentos religiosos e machistas tem assumido no Brasil um viés ultraintolerante e violento. Resta saber se os governos e outras instâncias reguladoras da vida social, como a escola e os meios de comunicação de massa, serão capazes de resistir ao tsunami de intolerância religiosa em curso e garantir um dos princípios fundamentais das sociedades democráticas: a laicidade do Estado.

Por fim, cabe sinalizar que lésbicas, gays, bissexuais, travestis e transexuais jamais conseguirão por si sós assegurar seu pleno acesso à cidadania e aos direitos humanos. O desafio maior parece ser construir uma aliança com os setores não conservadores da sociedade, particularmente outros movimentos sociais, a fim de garantir liberdade sexual e de gênero para quem não corresponde aos supostos padrões heterossexuais. Sem isso, a sociedade como um todo sofrerá um duro golpe, já que a redução de liberdades no âmbito da sexualidade e dos processos de representação do eu é ponta de lança para a instauração de lógicas totalitárias de controle em vários outros âmbitos da vida social.

Vivemos numa sociedade estruturalmente desigual, preconceituosa e violenta, que produz muitas vítimas cotidianas do preconceito, da discriminação e da intolerância em termos raciais, sexuais, de gênero, de classe, etários, relativos à gramática corporal. A novela da vida real, porém, nesse cenário escolhe os bodes expiatórios da vez, que são o objeto da ira mesmo daquelas pessoas que também são massacradas socialmente por não corresponderem às expectativas dominantes em termos econômicos, étnico-raciais, sexuais, etários, corporais. Um dos grandes desafios hoje, que é do movimento LGBT brasileiro, mas também do governo ou mesmo da sociedade civil em geral, é excluir a homossexualidade, a travestilidade e a transexualidade do rol das abominações sociais, que são objeto de uma intolerância disseminada, alimentada por discursos e práticas religiosas 
fundamentalistas, associando-se a um machismo que define o feminino como inferior, impuro, primitivo e irracional - bem como a não heterossexualidade como algo aberrativo, patológico ou anormal. Nesse sentido, sendo a profusão discursiva em torno da sexualidade inevitável, talvez uma subversão estratégica a ser efetivada, nos próprios termos do poder, como diria Foucault (1979), seja a construção de alianças entre o movimento LGBT e outros movimentos atinados à mudança social, desenvolvendo "políticas de solidariedade" (Facchini e França, 2009) de maneira a transformar toda a inaceitação social dirigida a questões relativas ao gênero e à sexualidade em um problema a ser enfrentado por todos, independentemente de suas escolhas em termos sexuais ou de suas performances de gênero.

\section{Referências}

ALMEIDA, Guilherme. Da invisibilidade à vulnerabilidade: percursos do "corpo lésbico" na cena brasileira face à possibilidade de infecção por DST e Aids. Tese (Doutorado em Saúde Coletiva) - Instituto de Medicina Social, Universidade Estadual do Rio de Janeiro, Rio de Janeiro, 2005

ANDRADE, Augusto José de Abreu. Visibilidade gay, cotidiano e mídia: Grupo Arco-Íris - consolidação de uma estratégia. Um estudo de caso. Dissertação (Mestrado em Comunicação) - Faculdade de Comunicação, Universidade de Brasília, Brasília, 2002.

ANJOS, Gabriele dos. A sexualidade é política. Atração, identidade e estratégias de manutenção em um grupo gay de Porto Alegre. Dissertação (Mestrado em Sociologia) Instituto de Filosofia e Ciências Humanas, Universidade Federal do Rio Grande do Sul, Porto Alegre, 1999.

BARROSO, Fernando Luiz Alves. Jornal do Nuances - a prática midiática de uma ONG de Porto Alegre (RS) para o confronto político entre o "gay classe média" e a "bicha bafona”. Tese (Doutorado em Ciências da Comunicação) - Universidade do Vale do Rio dos Sinos, São Leopoldo (RS), 2007.

BENEDETTI, Marcos Renato. Toda feita: o corpo e o gênero das travestis. Rio de Janeiro: Garamond, 2005.

BENTO, Berenice. A reinvenção do corpo: sexualidade e gênero na experiência transexual. Rio de Janeiro: Garamond, 2006.

BOURDIEU, Pierre. Questões de sociologia. Rio de Janeiro: Marco Zero, 1983.

BRAH, Avtar. Diferença, diversidade, diferenciação. Cadernos Pagu, no 26, p. 239-276, 2006.

BRAZ, Camilo et al. Movimentos sociais, direitos humanos e cidadania: um estudo sobre o movimento LGBT em Goiás. Relatório de Pesquisa. Goiânia: Ser-Tão - Núcleo de Estudos e Pesquisas em Gênero e Sexualidade/ Universidade Federal de Goiás, 2011.

BUtLER, Judith. Desdiagnosticando o gênero. Physis Revista de Saúde Coletiva, v. 19, no 1, p. 95-126, Rio de Janeiro, 2009.

CÂMARA, Cristina. Cidadania e orientação sexual: a trajetória do grupo Triângulo Rosa. Rio de Janeiro: Academia Avançada, 2002.
CARRARA, Sérgio. O Centro Latino Americano em Sexualidade e Direitos Humanos e o "lugar" da homossexualidade. In: GROSSI, Miriam Pilar et al. (Ed.). Movimentos sociais, educação e sexualidade. Rio de Janeiro: Garamond, 2005.

CONDE, Michele. O movimento homossexual brasileiro, sua trajetória e seu papel na ampliação do exercício da cidadania. Dissertação (Mestrado em Sociologia) - Faculdade de Ciências Sociais, Universidade Federal de Goiás, Goiânia, 2004.

DUQUE, Tiago . Montagens e desmontagens: desejo, estigma e vergonha entre travestis adolescentes. São Paulo: Annablume, 2011.

ERIBON, Didier. Reflexões sobre a questão gay. Rio de Janeiro: Companhia de Freud, 2008.

FACCHINI, Regina. Entre compassos e descompassos: um olhar para o "campo" e para a "arena" do movimento LGBT brasileiro. Bagoas: Revista de Estudos Gays, v. 3, n 4, p. 131-58, jan./jun. Natal, 2009.

FACCHINI, Regina. Sopa de letrinhas?: movimento homossexual e produção de identidades coletivas nos anos 90. Rio de Janeiro: Garamond, 2005.

FACCHINI, Regina; FRANÇA, Isadora Lins. De cores e matizes: sujeitos, conexões e desafios no Movimento LGBT brasileiro. Sexualidad, Salud y Sociedad - Revista Latinoamericana, no 3, p. 54-81, 2009.

FERNANDES, Felipe Bruno Martins. Muito prazer, sou Cellos, sou de luta: a produção da identidade ativista homosexual. Dissertação (Mestrado em Educação Ambiental) - Universidade Federal do Rio Grande, Rio Grande (RS), 2007.

FOUCAULT, Michel. História de sexualidade I. A vontade de saber. Rio de Janeiro: Graal, 1979.

FRANÇA, Isadora Lins. Cercas e pontes: movimento GLBT e mercado GLS na cidade de São Paulo. Dissertação (Mestrado em Antropologia Social) - FFLCH, Universidade de São Paulo, São Paulo, 2006.

FRY, Peter. Da hierarquia à igualdade: a construção histórica da homossexualidade no Brasil. Para inglês ver: identidade e política na cultura brasileira. Rio de Janeiro: Jorge Zahar, 1982. p. 87-115.

FRY, Peter; MACRAE, Edward. O que é homossexualidade? 
São Paulo: Jorge Zahar, 1983.

GREEN, James. Além do carnaval: a homossexualidade masculina no Brasil do século XX. São Paulo: Ed. Unesp, 2000.

GUIMARÃES, Carmen Dora. O homossexual visto por entendidos. Rio de Janeiro: Garamond, 2004.

KULICK, Don. Travesti: prostituição, sexo, gênero e cultura no Brasil. Rio de Janeiro: Fiocruz, 2008.

MACRAE, Edward. A construção da igualdade: identidade sexual e política no Brasil da "abertura". Campinas: Ed. Unicamp, 1990.

MELlO, Luiz (Org.). Políticas públicas para a população LGBT no Brasil: um mapeamento crítico preliminar. Relatório de pesquisa. Goiânia: UFG, Faculdade de Ciências Sociais, Ser-Tão, Núcleo de Estudos e Pesquisas em Gênero e Sexualidade, 2010. Disponível em: <http:// www.sertao.ufg.br/politicaslgbt>. Acesso em: 27 jul. 2011. MÍCCOLIS, Leila; DANIEL, Herbert. Jacarés e lobisomens - dois ensaios sobre a homossexualidade. Rio de Janeiro: Achiamé, 1983.

MOTT, Luiz. O lesbianismo no Brasil. Porto Alegre: Mercado Aberto, 1987.

PASSAMANI, Guilherme Rodrigues. O arco-íris (des) coberto. Santa Maria: Ed. UFSM, 2009.

PELÚCIO, Larissa. Abjeção e desejo: uma etnografia travesti sobre o modelo preventivo de Aids. São Paulo: Anablume, 2009.

PERES, William Siqueira. Subjetividade das travestis brasileiras: da vulnerabilidade dos estigmas à construção da cidadania. Tese (Doutorado em Saúde Coletiva) Universidade do Estado do Rio de Janeiro, Rio de Janeiro, 2005.

PERILO, Marcelo et al. Entre a aids e a integralidade: travestis, transexuais, bissexuais, lésbicas e gays nas políticas públicas de saúde no Brasil. In: MELLO, Luiz (Org.). Políticas públicas para a população LGBT no Brasil: um mapeamento crítico preliminar. Relatório de pesquisa. Goiânia: UFG, Faculdade de Ciências Sociais, Ser-Tão, Núcleo de Estudos e Pesquisas em Gênero e Sexualidade, 2010. p. 213-256.

SANTOS, Gustavo Gomes da Costa. Estado, projetos políticos e trajetórias individuais: um estudo com lideranças homossexuais na cidade de São Paulo. Dissertação (Mestrado em Ciência Política) - Instituto de Filosofia e Ciências Humanas, Universidade Estadual de Campinas, Campinas, 2006.

SANTOS, Patrícia Lessa dos. Lesbianas em movimento: a criação de subjetividades (Brasil, 1979-2006). Tese (Doutorado em História) - Universidade de Brasília, Brasília, 2007.

SANTOS, Regina Coeli Benedito dos. Raça, sexualidade e política: um estudo da constituição de organizações de lésbicas negras no Rio de Janeiro. Dissertação (Mestrado em Política Social) - Universidade Federal Fluminense, Rio de Janeiro, 2006.

SELEM, Maria Célia Orlato. A Liga Brasileira de Lésbicas: produção de sentidos na construção do sujeito político lésbica. Dissertação (Mestrado em História) - Universidade de Brasília, Brasília, 2007.

SILVA, Alessandro Soares da. Marchando pelo arco-íris da política: a Parada do Orgulho GLBT na construção da consciência coletiva dos movimentos LGBT no Brasil, Espanha e Portugal. Tese (Doutorado em Psicologia Social) - Pontifícia Universidade Católica de São Paulo, São Paulo, 2006.

SILVA, Vera Lúcia Marques da. Da espetacularização à agenda política: uma leitura política do movimento LGBT. Dissertação (Mestrado em Ciências Sociais) - Pontifícia Universidade Católica do Rio de Janeiro, Rio de Janeiro, 2008.

SIMÕES, Júlio Assis; FACCHINI, Regina. Na trilha do arco-íris: do movimento homossexual ao LGBT. São Paulo: Fundação Perseu Abramo, 2009.

TAQUES, Fernando José. Movimento GLBT em Santa Catarina: a questão do empoderamento. Dissertação (Mestrado em Sociologia Política) - Universidade Federal de Santa Catarina, Florianópolis, 2007.

TREVISAN, João Silvério. Devassos no paraíso. São Paulo: Max Limonade, 1986.

URANY, Alírio Melo. Ação coletiva e movimento GLBT em Goiânia. Dissertação (Mestrado em Sociologia) Faculdade de Ciências Sociais, Universidade Federal de Goiás, Goiânia, 2008. 


\title{
Debate on LGBT issues: challenges and achievements
}

\begin{abstract}
This paper presents reflections on the recent history of the LGBT movement in Brazil, emphasizing its main challenges and achievements. What stands out in this context is the contradictory nature of public debates on lesbians, gays, bisexuals, transvestites and transsexuals' citizenship, as their humanity does not seem widely recognized by society as a whole, and that the fundamentalist religious groups' discourses tend to question the formers' legitimacy as individuals who have rights from a political position that puts into question the State's laicism. A reflection on the roles played by the Executive, Legislative and Judicial powers in a context of moral and legal uncertainties is carried out, highlighting the relevance of creating a political culture that acknowledges the free expression of sexual orientation and gender performances, unrestrained by the parameters and values of the heterocentric norm.
\end{abstract}

Key words: social movements, LGBT activism, citizenship, sexual rights, Brazil.

\section{Debate sobre temas LGBT: retos y logros}

\section{Resumen}

Este texto presenta reflexiones sobre la historia reciente del movimiento LGBT en Brasil, con énfasis en sus principales retos y logros. Lo que se destaca en este contexto es el carácter contradictorio de los debates públicos acerca de la ciudadanía de lesbianas, gays, bisexuales, travestis y transexuales, ya que su humanidad no parece ampliamente reconocida por la sociedad en su conjunto y que los discursos de los grupos religiosos fundamentalistas tienden a cuestionar su legitimidad como sujetos de derechos desde una posición política que pone en tela de juicio el Estado laico. También reflexiona sobre el lugar del Ejecutivo, del Legislativo y del Judicial en un contexto de inseguridad jurídica y moral, poniendo de relieve la importancia de construir una cultura política que reconoce la libre expresión de la orientación sexual y actuaciones de género, más allá de los parámetros y los valores del estándar heterocéntrico.

Palabras-clave: movimientos sociales, activismo LGBT, ciudadanía, derechos sexuales, Brasil.

Data de recebimento do artigo: 13/09/2011

Data de aprovação do artigo: 01/02/2012 